\title{
New journal: Journal of Problem Based Learning in Higher Education
}

\section{New Open Access Journal on PBL to be launched in 2012/2013}

We are very happy to introduce a newly established peer reviewed journal titled: Journal of Problem Based Learning in Higher Education (PBLHE). The first issue of the journal is to be launched in winter 2012/spring 2013 following a call for paper sent out in spring 2012. PBLHE will be launched to provide an opportunity for scholars from all disciplines to publish:

- High-quality research articles that contribute to the current and future development of problem-based learning in higher education.

- Review articles examining the development of problem-based learning in higher education.

- Articles examining the intellectual, pedagogical and practical use value of PBL or which extend, critique or challenge past and current theoretical and empirical knowledge claims within PBL in higher education.

- Articles examining theoretical, pedagogical and practical aspects of how networked technologies or ICTs can be used to support or develop problem-based learning.

The coverage of the journal includes, but is not limited to:

- $\quad$ Principles and philosophy of PBL in Higher Education

- The pedagogy of PBL

- PBL and everyday practice

- $\quad$ PBL management and policy-making

- PBL and workplace cultures

- PBL and Creative Processes

- Critical PBL

- $\quad$ PBL, ICT and technology-enhanced learning

- $\quad$ PBL and networked learning

- PBL internships and cooperative education

- PBL and intercultural studies

- Interdisciplinarity and PBL

For more information please visit the journal web page: http://ojs.statsbiblioteket.dk/index.php/pbl/ . You can read more about the details of the editorial criteria and comprehensive instructions on how to submit a paper from the journal's author guidelines.

If you have any questions or comments please contact:

Thomas Ryberg, Associate Professor, MA, PhD. (ryberg@hum.aau.dk)

Aalborg University

Department of Communication and Psychology

Nyhavnsgade 14

DK-9000 Aalborg

Denmark

\section{Editorial board of Journal of Problem Based Learning in Higher Education:}

- Prof. Anette Kolmos (UNESCO Chair in Problem Based Learning), Aalborg University, Denmark

- Prof. Anthony Williams, Newcastle University, Australia

- Prof. Erik De Graaf, Delft University, Netherlands \& Aalborg University, Denmark

- Prof. Erik Laursen, Aalborg University, Denmark

- Prof. Lars Bo Henriksen, Aalborg University, Denmark

- Prof. Madeleine Abrandt Dahlgren, Linköping University, Sweden

- Prof. Paola Valero, Aalborg University, Denmark 
- Prof. Yves Mauffette, The Université du Québec à Montréal (UQAM), Canada

- Dr. Terry Barrett, University College Dublin, Ireland

- Associate Professor Khairiyah Mohd. Yusof, Universiti Teknologi Malaysia, Malaysia

- Associate Professor Thomas Ryberg, Aalborg University, Denmark

- Assistant Professor Diana Stentoft, Aalborg University, Denmark 